\title{
Expressivism and arguing about art
}

Daan Evers, University of Groningen (forthcoming British Journal of Aesthetics)

\begin{abstract}
Peter Kivy claims that expressivists in aesthetics cannot explain why we argue about art. The situation would be different in the case of morals. Moral attitudes lead to action, and since actions affect people, we have a strong incentive to change people's moral attitudes. This can explain why we argue about morals, even if moral language is expressive of our feelings. However, judgements about what is beautiful and elegant need not significantly affect our lives. So why be concerned with other people's feelings about art? Kivy thinks the best explanation of our tendency to argue about art is that we implicitly believe in objective facts about aesthetics. This would count against expressivism. I argue two things: (1) that there is no good reason to think that we don't care about preferences and emotions unless they have significant practical consequences and (2) that the truth of expressivism about aesthetic language is compatible with beliefs about objective aesthetic facts.
\end{abstract}

\section{Introduction}

In a recent book, and an older article, Peter Kivy argues that emotivists lack a plausible explanation of the fact that we argue about art. ${ }^{1}$ According to Kivy,

'[t]his is not the kind of behavior consistent with the premise that all we are doing when we call something beautiful, or a good work of art, is expressing our preference..$^{2}$

\footnotetext{
${ }^{1}$ Peter Kivy, De Gustibus. Arguing about Taste and Why We Do It (Oxford: OUP, 2015) and Peter Kivy, 'A Failure of Aesthetic Emotivism', Philosophical Studies 38 (1980), 351-365.

${ }^{2}$ Kivy, 'A Failure of Aesthetic Emotivism', 351.
} 
In his book, Kivy suggests that the best explanation of the phenomenon - barring certain exceptions - is that we implicitly believe in objective facts about beauty and artistic merit. My aim in this paper is to formulate an answer to Kivy's challenge on behalf of emotivism. I will proceed as follows: in section 1, I explain Kivy's challenge. In section 2, I explain why it also extends to more sophisticated forms of expressivism. In section 3, I suggest that we lack good reason to think that we are indifferent to other people's preferences. In section 4 , I argue that the truth of expressivism is compatible with implicit beliefs in objective facts about aesthetics.

\section{Kivy's Case}

Kivy claims that an adequate account of aesthetic language should be able to explain why we argue about art:

'the emotive analysis of aesthetic discourse - or any analysis, for that matter must allow for a plausible account of aesthetic disagreement. ${ }^{3}$

Of course, disagreeing is one thing and arguing another, but Kivy is interested in the fact that diverging judgements about aesthetic or artistic features give rise to "disagreement behaviour": attempts to convince the other of one's viewpoint. It is the latter that requires explanation.

Kivy assumes that disagreement behaviour requires no special explanation if there are facts about the matter at hand. People clearly argue about facts, so whatever explains that can presumably be transferred to an arbitrary subject. What is less clear

\footnotetext{
${ }^{3}$ Ibid., 357.
} 
is why we should argue about things that are a matter of preference or emotional response, which is what the emotivist believes about aesthetic judgements: they would be non-cognitive states (like preferences or emotions), as opposed to representations of a way the world is.

When Kivy says that we argue about art, he means that we argue about at least three things related to artworks: (1) their content- or meaning-properties, (2) their evaluative aesthetic features and (3) their overall artistic quality or goodness.

Content- or meaning-properties concern symbolic and representational properties of artworks. Examples are a dab of paint representing the Sun, a sculpture symbolizing desperation, and a protagonist being egocentric (or represented as such). Although people disagree about such features, content-properties present no special problem for emotivism. Emotivism is not a theory about (this kind of) representation. Either there are facts about what a work represents or means, or there are not. If there are, then emotivists can invoke whatever it is that explains our tendency to argue about facts quite generally. If there are not, then disagreement behaviour about content-properties is a problem for any account of aesthetic discourse. ${ }^{4}$

The interesting cases are evaluative aesthetic features, such as beauty, ${ }^{5}$ elegance and garishness, and evaluative artistic properties, like how good or successful a work is on the whole.

Insofar as calling something beautiful or elegant is at least in part evaluating it, emotivists think the evaluation is a matter of emotional or attitudinal response.

\footnotetext{
${ }^{4}$ As Kivy notes, scepticism about content-properties is likely to trace back to scepticism about meaning or representation more generally.

${ }^{5}$ In the narrow sense, where it contrasts with sublimity or prettiness. 'Beauty' can also be used as a generic term for overal artistic quality, in which case it would fall under the third category of evaluative artistic properties.
} 
Although we may speak about evaluative properties in a deflationary sense, there are no evaluative aspects of reality, and the function of evaluative language is to express (but not describe) our attitudes towards the world. Of course, terms like 'elegant' and 'garish' may be thick evaluative terms, often thought to have both descriptive and evaluative content. ${ }^{6}$ If so, then their meaning is not entirely emotive. But the point remains that the evaluative aspect of their meaning is not a matter of propertyascription.

Terms like 'artistically good' and 'artistic merit' can be compared to thin evaluative terms like 'right' or 'wrong' in ethics. Emotivists may think these terms carry no particular descriptive information as part of their linguistic meaning. If so, then they are "pure" expressions of emotion (preference, etc.). Alternatively, they may think that they have both descriptive and evaluative content distinct from that involved in thick evaluative terms.

Kivy wants to know how the emotivist could explain our tendency to argue about evaluative aesthetic and artistic features (henceforth I will simply use 'aesthetic features' to refer to both). This question presupposes that we $d o$ argue about them. Kivy realizes that not everyone argues about aesthetic judgements, but claims that this hardly distinguishes disagreement behaviour about art from disagreement behaviour about any other topic. After all, not everyone argues about the extinction of the dinosaurs either, or the way the pyramids were built. Some people simply lack the interest to engage. What requires explanation is the behaviour of a class of people Kivy calls the art-interested. These include laypeople and professionals sufficiently 
interested to argue about whether some art was great or unsuccessful, moving or insipid, well-balanced or uneven, etc.

Kivy is convinced that this behaviour exists:

'That the art-interested $d o$ dispute over the presence or absence of [aesthetic] features seems itself indisputable. When the art-interested, either at the low end of the expertise scale, or the high end, or in between, congregate after seeing a movie or play, or after reading a novel in a book club, or standing before a painting in a museum, they surely do converse about what they have experienced. And they surely do not simply say "I liked it" or "I didn't," "It's good," or "It isn't." They may indeed say all of these things. They will not, however, leave it at that, usually, if they are the art-interested, and if they do disagree. They will try to convince others of their judgments. ${ }^{7}$

Kivy does not describe exactly how the art-interested try to convince others of their judgements, but art criticism is illuminating. Take the following fragment from a review of the film Boyhood by Bob Cesca:

'[...] the basic elements of storytelling need to exist in order to carry us through. Showing various and random vignettes of a kid's life is fine as long as those vignettes inform the narrative rather than simply take up time. A strong narrative thread is, for lack of a more academic word, entertaining.

\footnotetext{
${ }^{7}$ Kivy, De Gustibus, 128-129.
} 
There's a reason why movies are supposed to be a reflection of real life, and not literally real life. Real life is often boring and anti-climactic. ${ }^{8}$

Cesca is trying to persuade us that the film is lacking in narrative interest, by drawing our attention to the fact that different episodes in the protagonist's life lack a function in a larger story. This suggests a general characterization of the method used to persuade others of one's aesthetic judgements: the art-interested proceed by pointing out evaluative and non-evaluative features that they assume will be recognized by the intended audience to indicate a lack of overall merit, or the presence of sentimentality, elegance, etc. ${ }^{9}$ Kivy thinks that the emotivist has no good explanation of most instances of this behaviour.

In the case of ethics, emotivists appeal to our interest in changing people's conduct:

'ethical judgments $[. .$.$] are deeply involved with the incitement to and the$ prohibition of actions, many of which I or those I care about may have a personal stake in. And it is an obvious step in my getting someone to do what I want him to do or not do is to get him to share my ethical emotion, my

\footnotetext{
${ }^{8}$ Bob Cesca, 'It's Ok if You Didn't Like 'Boyhood', and Here are Many Reasons Why', (published online February 2015) <https://www.huffingtonpost.com/bob-cesca/its-okay-if-you-didnt-likeboyhood_b_6694772.html>, accessed October 2017.

${ }^{9}$ A referee for this journal points out that people may not always do this, and that there are limits to the possibilities of persuading others. For example, if one's discontent with a work is due to preferences for certain colours, it may be hard to persuade another of one's judgement. However, the fact that there are limits to the practice does not show that it does not exist, or that there is nothing to be explained.
} 
attitude of approval of what I want him to do and to get him to share my ethical emotion, my attitude of disapproval of what I want him not to do. ${ }^{10}$

But Kivy argues that even if this idea has merit in the case of ethics, it has none in the case of art. Attitudes towards art would not be connected to action in a way that could motivate us to try to change them. The idea is not that aesthetic attitudes are not connected to action at all, but rather that what they lead people to do is not something most of the art-interested could plausibly be motivated to change. Appreciating certain works primarily leads to (or consists in?) enjoying them, and secondarily to a disposition to choose to engage with them rather than others. ${ }^{11}$

The fact that enjoying certain works is connected to choice might suggest that we have an interest in influencing people's attitudes at least in certain circumstances (we may want to get the local curator to buy a certain work, or we may have to spend an evening together). However, most of the people we come across - and are prepared to argue with - cannot significantly affect our ability to see, read or hear the art that we prefer. So Kivy believes that this motive cannot explain most cases of arguing about aesthetic judgements.

An alternative is to appeal to a benevolent motive, since appreciating works is connected to enjoyment. However, this does not explain our tendency to dissuade others from their positive judgements.

\footnotetext{
${ }^{10}$ Kivy, De Gustibus, 33.

${ }^{11}$ Kivy also discusses the possibility that people take there to be some relation between appreciating certain works and moral character, which would allow the emotivist to appeal to indirect connections to action after all. But this hypothesis strikes both me and Kivy as implausible. It is also unlikely that all discussion about the quality of art boils down to discussion of the moral significance of the work itself.
} 
Kivy also discusses the idea that 'we have [...] a deep-seated need to feel a sense of community [...] with others, and therefore a need for them to share our attitudes, our aesthetic and artistic attitudes included'. ${ }^{12}$ This need cannot be explained by the practical importance of sharing aesthetic attitudes (since they are not suitably connected to action), but we might have it nonetheless. However, Kivy claims that there is no evidence for this hypothesis, and some evidence against. The evidence against would consist of the fact that we also appreciate variety in taste. I will return to this in section 3 .

Kivy's criticism of the need hypothesis is relevant to A.J. Ayer's ideas about aesthetic discussion. ${ }^{13}$ Ayer suggests that arguments about art concern factual (nonevaluative) features of artworks, which might seem promising as there is no special problem accounting for arguing over facts. But he also suggests that our purpose in pointing out such features is to get others to share our emotional response. The latter brings us back to the question why we should be motivated to do that in the first place:

'After all, there is no such compulsion for me to get you to share my positive emotion towards cheeseburgers or Golden Retrievers. It is all the same to me whether you share them with me or not. ${ }^{14}$

Since Kivy fails to see any alternatives to the options mentioned, he concludes that emotivism lacks a plausible explanation of aesthetic disagreement behaviour. His

\footnotetext{
${ }^{12}$ Ibid., 43.

${ }^{13}$ Alfred Ayer, Language, Truth and Logic (London: Victor Gollancz Ltd, 1936).

${ }^{14}$ Kivy, De Gustibus, 32-33.
} 
own suggestion is that we argue about aesthetic features because we are implicitly aesthetic realists: we believe that there are objective facts about beauty, elegance and the artistic quality of artworks. This allows us to refer the explanation of disagreement behaviour to whatever it is that explains our interest in getting the facts right.

Ayer's claim that aesthetic dispute always concerns non-evaluative features, or the idea that aesthetic language also has descriptive meaning, might seem to help in answering the challenge more than Kivy allows. For although Ayer suggests that our purpose in pointing out non-evaluative features is to get others to share our emotional response, he may not need the add-on. If differences in emotional response are explained by mistakes about the non-evaluative features of art, then perhaps we can explain disagreement behaviour with reference to our interest in the facts.

But things are not so simple. One problem is that some differences in emotional response are explained not by false beliefs about a work, but by ignorance of some of the work's non-evaluative properties (I may not have noticed references to $\mathrm{X})$. It is not clear that we have the same interest in getting people to have more knowledge about things as we have in correcting false beliefs.

Perhaps the foregoing is not decisive. People who disagree about art might still believe that their disagreement is explained by false beliefs about non-evaluative features (beliefs that references to $\mathrm{X}$ are absent, say). But another, more serious problem is that we can imagine a scenario in which we agree on all the non-evaluative properties of a work, while still disagreeing about its beauty or artistic value. If our tendency to argue were explained by our interest in true beliefs about the nonevaluative facts, then agreeing on those facts should leave us satisfied. That may not 
be so. ${ }^{15}$ Another reason to doubt that all that we are interested in is getting the nonevaluative facts straight, is that it frequently happens that someone points out in what respects a work should have been different. ${ }^{16}$ That cannot be explained by an interest in a work's actual descriptive features only.

As indicated, Kivy believes that the correct explanation of disagreement behaviour is that we implicitly believe in objective facts about aesthetics. It is not clear what Kivy means by 'objectivity'. The sketch of his own view about aesthetic features suggests a kind of Humean naturalism, according to which an artwork is good (elegant, etc.) in virtue of eliciting a certain response from all suitably qualified judges. ${ }^{17}$ If that is indeed his view, then Kivy may not think that people are committed to the existence of response-independent facts about aesthetic features (although that is also compatible with everything else asserted in the book). For the purposes of this paper, it does not matter very much exactly what is meant by an objective fact. I will argue that expressivism can explain the phenomena without postulating beliefs in aesthetic facts of any kind, and that expressivism is compatible with beliefs in objective facts on whatever understanding of the term.

\section{The General Nature of the Challenge}

Before suggesting an answer to Kivy's challenge on behalf of emotivism, let me briefly explain why it extends to more sophisticated forms of expressivism too.

\footnotetext{
${ }^{15} \mathrm{~A}$ drawback of this argument is that we may be less certain whether disagreement behaviour would persist in the face of beliefs that others had all the right factual beliefs about a work.

${ }^{16}$ I owe this argument to Kritika Maheshwari.

${ }^{17}$ Ibid., 119-136.
} 
Emotivists about aesthetic language believe that evaluative claims about art express the speaker's non-cognitive attitudes towards the work in question. Such attitudes might be emotions, but can also be preferences or different kinds of state (Ayer says that critics express their 'feelings' towards artworks with the aim of getting others to share their 'attitudes'). One can either consider this idea as an account of the linguistic meaning of aesthetic terms or as an account of the use to which they are put (the latter would then allow that normative and evaluative language are strictly speaking meaningless, for instance). Kivy's challenge applies even if we interpret emotivism as a theory about the use (as opposed to linguistic meaning) of aesthetic terms, insofar as the purpose for which they are used precludes an explanation of disagreement behaviour in terms of an interest in getting the facts right. However, it is standard to interpret emotivism as a theory about the linguistic meaning of evaluative terms, so I will assume this in what follows.

The claim that evaluative terms must be understood as expressive of noncognitive states doesn't distinguish emotivism from more sophisticated forms of expressivism, such as Blackburn's ${ }^{18}$ or Gibbard's versions of the theory. ${ }^{19}$ Potential differences consist in the kind of attitude expressed by an evaluative sentence, and the lack of detail in the emotivist's treatment of evaluative discourse (Ayer and Stevenson say very little about embedding or logical validity). However, it is not clear whether Blackburn's view is distinct from emotivism with respect to the mental states expressed, as both he and emotivists are vague and liberal in their descriptions.

\footnotetext{
${ }^{18}$ Simon Blackburn, Spreading the Word (Oxford: Clarendon Press, 1984) and Simon Blackburn, Ruling Passions (Oxford: Clarendon Press, 1998).

${ }^{19}$ Allan Gibbard, Wise Choices, Apt Feelings (Oxford: Clarendon Press, 1990) and Allan Gibbard, Thinking How to Live (Harvard: Harvard University Press, 2003).
} 
Gibbard does distinguish himself by taking a specific view about the mental state expressed by evaluative language. In earlier work, he takes it to be a state of norm acceptance, ${ }^{20}$ whereas in later work, he thinks it is a state of planning. ${ }^{21}$ Kivy's $^{\prime}$ challenge extends to Gibbard's views, since it is no more clear why we should want others to share our aesthetic norms or plans than that we should want them to share our emotional responses.

Some forms of expressivism claim that moral claims involve imperatives, such as Stevenson's analysis of 'X is good' as 'I approve of X, do so as well!', ${ }^{22}$ or Hare's prescriptivism. ${ }^{23}$ This marks a difference with both Ayer's emotivism and Blackburn's and Gibbard's theories. However, the move to imperatives does not help in answering Kivy's challenge. The aim of addressing imperatives to others is presumably to get people to change their attitudes, but the question is why we should be motivated to do SO.

Some versions of expressivism involve the idea that evaluative claims are both expressive and descriptive, such as Stevenson's, ${ }^{24}$ Hare's ${ }^{25}$ and Michael Ridge's. ${ }^{26}$ The descriptive content would concern properties of the object of evaluation, including

\footnotetext{
${ }^{20}$ Gibbard, Wise Choices, Apt Feelings.

${ }^{21}$ Gibbard, Thinking How to Live.

${ }^{22}$ Charles Stevenson, 'The Emotive Meaning of Ethical Terms', Mind 46 (1937), 14-31.

${ }^{23}$ Richard Hare, The Language of Morals (Oxford: Clarendon Press, 1959).

${ }^{24}$ Stevenson, The Emotive Meaning of Ethical Terms.

${ }^{25}$ Hare, The Language of Morals.

${ }^{26}$ Michael Ridge, Impassioned Belief (Oxford: OUP, 2014). Ridge is somewhat more difficult to place, as he currently takes expressivism to be a metasemantic theory about how moral words acquire their linguistic content. However, it seems unlikely that this content could be a matter of robust factual description, since that would expose expressivism to all the problems associated with descriptivist views in metaethics.
} 
relational properties like its meeting certain standards, or being approved of by the speaker. Kivy would say that this does not help either so long as the primary reason for arguing about art is not to get those particular facts right, but to change each other's attitudes.

\section{Arguing about Cheeseburgers and Golden Retrievers}

Kivy rejects the idea that we have a need to share emotions and preferences quite generally. This is motivated by reference to cheeseburgers and Golden Retrievers. We are supposed to be indifferent whether others share our preferences (or "positive emotions") about those. This raises the question why we should be interested in changing people's preferences in the case of art.

It is not obvious that we are indifferent to people's preferences even when it comes to food and pets. Don't food critics engage in something that is in relevant respects indistinguishable from art criticism? Would it be surprising if someone argued that Golden Retrievers are inferior to Huskies? Even if there are differences in the extent to which we cultivate debate about such preferences, one might reasonably doubt whether there is a principled difference with art.

Of course, we also tolerate differences in taste in food and dogs, but this is no point of contrast either. Many people, including the art-interested, are happy to accept that others find a certain work beautiful or elegant, or that they prefer Monet to Mondriaan.

Perhaps fewer people are interested in arguing about food, or fewer people on fewer occasions. But this can be explained in ways that are nothing to do with the presence or absence of beliefs in objectivity. For instance, cheeseburgers do not stir 
any significant emotions apart from gustatory delight in ordinary people, whereas art is more meaningful to us (or to those who care to argue).

Another reason why people might be more inclined to argue about art is that art has different status in (our) society. People may not want to seem unsophisticated in their taste in art, and to defend their judgements more than in the case of food. The fact that art has an elevated status might itself be explained by beliefs in objective facts about aesthetics, but that is not the only explanation (nor clearly the best). Appreciation of certain kinds of art might be associated with higher social classes, or have other contingent historical roots.

Perhaps debate about the quality of art tends to be more elaborate than debate about food or dogs. This can be explained by the nature of art and food, respectively. Ayer was right that aesthetic debate ordinarily focuses on non-evaluative features. This is to be expected, since aesthetic features are the ones under dispute, and the non-evaluative features (in part) explain our judgements about evaluative ones. In the case of art, there is (often) more to talk about. Many artworks involve storylines and symbolism. Art that lacks such features still exemplifies values or traditions. Although food can have interesting historical properties, it typically lacks representational and symbolic content. Most food does not try to make a point.

This leaves us with some doubt that we don't argue about matters of preference. We are often interested in the reasons why people like a certain thing, and are moved to express our disagreement. If so, then an important premise in Kivy's argument is undermined. Kivy relies on a contrast between debate about matters of fact and matters of preference or emotion. Since we wouldn't argue about preferences for dogs or cheeseburgers, debate about art would be hard to explain for the expressivist about aesthetic language. If there appears to be no significant difference 
between our tendency to argue about preferences and facts in the first place, then his argument is not persuasive.

Of course, Kivy might say that whenever we $d o$ argue about dogs or cheeseburgers, we presuppose that there are facts to be discovered. The problem with that suggestion is that it was supposed to be motivated by the absence of disagreement behaviour about dogs and cheeseburgers. If we do argue about them, then this motivation disappears.

The foregoing leaves it open that the idea that we presuppose objective facts when arguing about food can be motivated in some other way. Perhaps the following is one: some people try to end debate by saying that the subject is a matter of taste. The reason this works might be that it draws attention to the fact that preferences are not answerable to objective facts about value. ${ }^{27}$ If so, then people find explicit beliefs about the arbitrariness of preferences an obstacle to reasonable argument. In that case, it is insufficient for a defence of expressivism to point out that we do argue about food and dogs. For such arguments may themselves presuppose beliefs in objective facts about value.

But again there is an alternative explanation of the phenomenon. Aesthetic debate may ordinarily proceed on the assumption that others share emotional dispositions (in fact, Kivy explicitly accepts this ${ }^{28}$ ). If so, then drawing attention to the fact that the topic is a matter of taste might block debate by negating that assumption, as opposed to a belief in objective facts about the subject.

\footnotetext{
${ }^{27}$ Of course, saying that a subject is a matter of taste carries the implicature that the speaker has had enough of the debate or that everyone is entitled to their own opinon, which may also explain why people then stop arguing. However, the question remains why saying that in particular should be effective, if topics that are explicitly considered as matters of taste are quite happily debated.

${ }^{28}$ Kivy, De Gustibus, 20.
} 
This leaves us with the conclusion that there is no strong evidence that we are indifferent to other people's preferences and emotions. Now, Kivy did say that there is no evidence for a need to share preferences or emotions. But this assertion is dubious if we do in fact argue about all kinds of preferences. He also said that there was evidence against it, consisting of the fact that we appreciate variety in taste. However, the fact that we appreciate variety in taste does not mean that we don't also appreciate communion. Various elements in our psychology can explain some of our behaviour some of the time.

None of the foregoing provides an explanation of our interest in comparisons of taste. I don't pretend to have one, although I suspect it is connected to our social nature. Clearly, awareness of shared preferences or emotions is often pleasant in itself, ${ }^{29}$ and dissent can be unpleasant. This might be enough to motivate us to argue about aesthetic judgements.

\section{Expressivism and Beliefs in Objective Facts}

There is another way to answer Kivy's challenge. The challenge is to explain why the art-interested might argue about art, if aesthetic statements express preferences or emotions. Since we would lack a need to share preferences and emotions, and since most debate involves nothing of practical importance, it would be hard to explain why the art-interested argue about aesthetic judgements. No such problem would arise if people believe in objective facts about aesthetics. If the latter is right, then another

\footnotetext{
${ }^{29}$ Daan Evers \& Natalja Deng, 'Acknowledgement and the Paradox of Tragedy', Philosophical Studies 173 (2015), 337-350.
} 
response on behalf of expressivism is to argue that its truth is compatible with the fact that people who argue about art believe in objective facts about aesthetic features.

It may seem unlikely that people believe in objective facts about aesthetics, as a popular proverb takes it to be fruitless to argue about taste. ${ }^{30}$ But Kivy would say that although people think they are subjectivists about aesthetic features, they subconsciously assume that there are objective facts about such features. The implicit belief would be revealed in their argumentative behaviour.

Although Kivy never says so explicitly, it is natural to interpret him as arguing against expressivism via its inability to explain why we argue about art. Kivy is looking for 'motives for arguing over matters of taste that $[\ldots]$ are compatible with the disputant's belief that our aesthetic judgments are expressions of positive or negative attitudes, not expressions of beliefs about the way the world is'. ${ }^{31}$ This seems to presuppose that if expressivism about aesthetic language were true, then ordinary people would know about it. An initial reason for doubting this is that even philosophers disagree about the correct semantics of aesthetic language. So why should ordinary people know that their aesthetic claims are expressions of their attitudes?

Some philosophers consciously believe that aesthetic claims describe (objective) facts, and there is no reason to doubt their competence with aesthetic terms. ${ }^{32}$ Others, whose competence is no more in doubt, consciously believe that

\footnotetext{
${ }^{30}$ I owe this objection to an anonymous referee for this journal.

${ }^{31}$ Kivy, De Gustibus, 42.

${ }^{32}$ Eddy Zemach, Real Beauty (University Park, Pennsylvania: The Pennsylvania State University Press, 1997), Thaddeus Metz, Meaning in Life (Oxford: OUP, 2013), Kivy, De Gustibus.
} 
aesthetic language is expressive of our attitudes. ${ }^{33}$ This appears to show that the meaning of aesthetic terms is not apparent to most people competent with them (on the assumption that there is one uniquely correct semantics). If so, then it may both be true that expressivism is the correct account of aesthetic language, and that those willing to argue about aesthetic judgements believe in objective facts about aesthetics.

We might even provide an explanation of the compatibility. Michael Smith suggests that knowledge of meaning is a kind of know-how, as opposed to knowledge-that. ${ }^{34}$ Mastery of words does not consist in an ability to articulate definitions, or to explicate their meaning in theoretical terms. ${ }^{35}$ If this is right, then whatever it is that constitutes knowledge of the meaning of a word need not be fully consciously accessible.

Michael Ridge suggests something along similar lines:

'[...] understanding the meaning of a word is better explicated in terms of knowing how to use the word properly rather than knowing that it means such and such. Expressivism might be a good theory of the sort of know-how associated with moral vocabulary even if ordinary speakers do not have knowledge that it is. ${ }^{36}$

\footnotetext{
${ }^{33}$ Roger Scruton, Art and Imagination (South Bend, Indiana: St. Augustine's Press), Blackburn, Ruling Passions.

${ }^{34}$ Michael Smith, The Moral Problem (Oxford: Blackwell, 1994).

${ }^{35}$ Smith believes that this explains why conceptual analysis is hard, and that it provides a solution to the paradox of analysis.

${ }^{36}$ Michael Ridge, 'How Children Learn the Meanings of Moral Words: Expressivist Semantics for Children', Ethics 114 (2004), 301-317, at p. 303.
} 
However, it's not clear that a generic appeal to know-how as opposed to knowledge-that suffices to respond to Kivy. After all, no ordinary speaker believes that 'Hurray!' and 'Ow!' describe objective facts. That is very plausibly explained at least in part by people's linguistic mastery of the expressions. In fact, for any expression whose function is uncontroversially different from description, ordinary speakers' linguistic knowledge blocks the formation of beliefs about objective facts (think of imperatives or greetings). This counts against the idea that the truth of expressivism can easily lead to beliefs in objective facts about aesthetics, and suggests that the truth of an objectivist semantics may be more easily combined with diverse beliefs about the nature of aesthetic language.

So the expressivist needs to explain why people should form beliefs in objective aesthetic facts when they don't form beliefs in objective facts corresponding to imperatives or greetings. One obvious suggestion is that the grammar of evaluative language is the same as that of descriptive language. Grammar may blind people to the fact that it really serves a different purpose. However, it is not clear how plausible this is. Why should we believe that grammar as opposed to semantic content plays the dominant role in explaining people's beliefs about the purpose of the language ${ }^{37}$ Suppose there were a language which allows people to perform the speech act of accosting via a sentence with subject-predicate form, as in Dreier's Hiyo-example. ${ }^{38}$ (Dreier stipulates that 'Bob is Hiyo' means the same as 'Hiyo, Bob', whose meaning is explicated in terms of the speech act of accosting Bob.) Would we expect speakers of

\footnotetext{
${ }^{37}$ Furthermore, even if speakers did believe that aesthetic language was descriptive, we need them to believe that it describes objective facts (as it equally hard to understand disagreement behaviour if aesthetic claims described facts about the speaker's psychology).

${ }^{38}$ James Dreier, 'Expressivist Embeddings and Minimalist Truth', Philosophical Studies 83 (1996), 2951.
} 
this language to be unaware that 'Bob is Hiyo' could not describe a fact? Since that is very doubtful, a mere appeal to grammar is not entirely convincing.

In order to explain why the truth of expressivism about aesthetic language is compatible with beliefs about objective facts, the expressivist should probably appeal to the nature of aesthetic experience. The use of aesthetic terms is prompted by certain experiences. That does not by itself distinguish aesthetic terms from 'Hurray!' or 'Ow!', but there are differences in the nature of the experiences with which their appropriate assertion is correlated. Many aestheticians believe that experiences of beauty are phenomenologically objective: beauty either appears to us as a mindindependent feature $\left(\mathrm{Hume}^{39}\right)$, or the responses that constitute the experience of beauty appear to us as merited by the object in question (Kant). Pain experiences lack such phenomenological qualities, as do the states expressed by greetings or imperatives. The expressivist could appeal to these differences in order to explain why people might develop beliefs in objective facts about aesthetics: the state expressed by aesthetic terms appears to us to represent an objective property, or as objectively merited by the object of response.

\section{Conclusion}

Peter Kivy argues that expressivists about aesthetic language cannot explain why we argue about art. Whereas expressivists about moral language can appeal to the practical importance of moral attitudes, this explanation would be unavailable in the case of aesthetics. There would also be evidence that we don't care whether others share our attitudes quite generally, making it hard to see how the expressivist could

\footnotetext{
${ }^{39}$ At least in Kivy's reading.
} 
explain disagreement behaviour about aesthetic features. I have argued two things: first, that there is no strong evidence that we are indifferent to others people's attitudes, and second, that the truth of expressivism is compatible with beliefs in objective facts about aesthetics. This gives the expressivist two lines of response to Kivy's challenge.

\section{Acknowledgements}

I would like to thank Kritika Maheshwari, Herman Veluwenkamp, Neil Sinhababu and an anonymous referee for the British Journal of Aesthetics for useful discussion of this paper. 